\title{
Speed Profile as a Tool to Estimate Traffic Calming Measures Efficiency
}

\author{
Robert Ziolkowski \\ Faculty of Civil and Environmental Engineering, Department of Road Engineering, Bialystok University of Technology, Bialystok \\ 15-351, Poland
}

\begin{abstract}
TCMs (traffic calming measures) are commonly installed in order to reduce speeds and volumes of traffic to acceptable levels and, thus, improve traffic safety as well as environmental impact when designed appropriately as a corridor or aerial implementation with proper spacing. Hence in many previous studies, their impact was mainly evaluated in scope of average and 85th percentile speed reduction. This paper presents and appraises the efficiency of calming measures of various types used in the city of Bialystok, Poland in terms of their influence zone. The assessment is based on speed profiles derived from individual test rides conducted with test vehicle equipped with GPS (global positioning system) data logger to obtain vehicle trajectory data. Speed measurements were conducted in vicinity of most commonly installed calming measures such as speed cameras, raised pedestrian crossing, raised intersection, speed bumps and speed cushion. The results reveal great differences within analysed devices and the usefulness of speed profiles in evaluation of their effectiveness. Speed bumps, most frequently used device in practice due to their low cost installation and speed reduction effectiveness, demonstrate lowest usefulness when influence zone is considered.
\end{abstract}

Key words: Traffic calming measures efficiency, speed profiles, influence zone.

\section{Introduction}

Nowadays, the problem of speeding drivers is a worldwide known issue and leads to exploring effective way of speed management especially in urban areas where most of accidents occur. Traffic safety reports from many countries show [1, 2] that speed and speeding are at the core of the road safety problem and are a causation factor in around one third of fatal accidents. Hence, arises a need for effective speed control and reduction. Traffic calming being a part of speed management can be recognized as aerial solutions including the whole residential zone, linear installations including chosen streets and spot when measures are installed in locations that require special attention. All these solutions are used to improve traffic safety and environmental impact. Implementation of TCMs

Corresponding author: Robert Ziolkowski, Ph.D., research fields: traffic safety and management, analysis of speed and drivers' behaviour, road engineering and ITS. E-mail: robert.ziolkowski@pb.edu.pl. (traffic calming measures) in Polish conditions mainly comes from the necessity of control excessive speed which is a major contributor in the number of accidents, deaths and serious injuries on roads. Calming devices such as speed bumps and speed raised medians most commonly implemented due to their cost effectiveness while issues related to other aspects of their efficiency are not considered.

Traffic calming schemes incorporate a wide range of measures intended to both reduce speed and enhance the environment although the effectiveness varies according to the measures employed [3]. Their efficiency has been proved in many countries $[4,5]$ but was mainly focused on speed reduction of a specific measure [6-12] and safety improvements [13-15].

Speed measurements and data collection are key issues in proper research performing. Moreno and García [16] built a model of speed profiles for roads with a sequence of calming measures used for data collection of 16 sets of pneumatic tubes fixed onto the 
roads. Spaces between sensors and calming devices ranged from 7 24 m depending on the survey site.

Elvik [15] presented the usage of continued speed profiles derived from GPS (global positioning system) tracker for different TCM spacing to evaluate the safety effectiveness of TCMs on crosstown roads and Barbosa et al. [17] used a probe vehicle equipped with a GPS device to evaluate the effectiveness of various calming measures based on a more complete evaluation framework that considered traffic performance, traffic safety, and environmental and public health impacts using a microscopic approach. They built a microscopic traffic simulation model on the basis of speed profiles derived for four traffic calming measures typically installed in residential areas in Korea.

In many countries, traffic calming measures most frequently operate separately and their effectiveness is limited to short distances and is more believed to cause only disturbance in traffic flow and smoothness than effectively control speeds [18]. Nevertheless, their impact on drivers' behaviour is poorly recognized in terms of influencing zone and available literature is rather limited.

Hence, the objective of this study emerges which is the evaluation of the effectiveness of various types of TCMs based on individual speed profiles in terms of influencing zones.

\section{Site Specification and Data Collection}

Speed measurements were conducted in the city of Bialystok, a middle-size town in Poland with about 300,000 inhabitants. The city suffers from speeding drivers and posted speed limits are frequently exceeded. To overcome this problem, city department of transportation preventing drivers from speeding has installed a number of traffic calming measures. Majority of them works as individual installations except few schemes which create a kind of calmed corridors or cover whole residential area. However, those complex schemes were excluded from this study. From a variety of calming measures implemented in Bialystok, most effective in forcing drivers to slow down are vertical deflections namely speed bumps [19]. Present investigation concentrates on various types of vertical deflections functioning as independent implementations and includes all types of measures present in the city. However, having regard the fact that presently the use of speed cameras is widespread around the country as a prevention from speeding, the scope of the study has been extended to those devices as well.

Examined measures therefore are :

- speed camera;

- raised intersection;

- raised pedestrian crossing;

- speed bump;

- speed cushion;

- raised median island.

Characteristics of streets where calming devices are installed and speed measurements were performed are presented in Table 1. In the area of speed bumps and raised pedestrian crossings installations, there exist warning signs with decreased speed limits to according $20 \mathrm{~km} / \mathrm{h}$ and $30 \mathrm{~km} / \mathrm{h}$. Schemes of analysed speed bumps and speed cushion are presented in Fig. 1.

Speed measurements were conducted with the use of GPS data logger enabling to monitor and register

Table 1 Characteristics of street with calming measures.

\begin{tabular}{llll}
\hline Type of calming measure & Type of a cross section & Type of a street & Administrative speed limit $(\mathrm{km} / \mathrm{h})$ \\
\hline Speed camera & $2 / 2$ & Arterial street & 50 \\
Raised intersection & $1 / 2$ & Residential street & 50 \\
Raised pedestrian crossing & $1 / 2$ & Residential street & 40 \\
Speed bump & $1 / 2$ & Collector street & 50 \\
Speed cushion & $1 / 2$ & Residential street & 50 \\
Raised median island & $1 / 2$ & Residential street & 50 \\
\hline
\end{tabular}




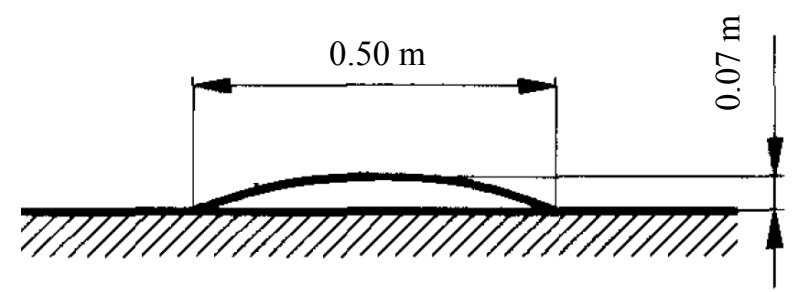

$2.00 \mathrm{~m}$

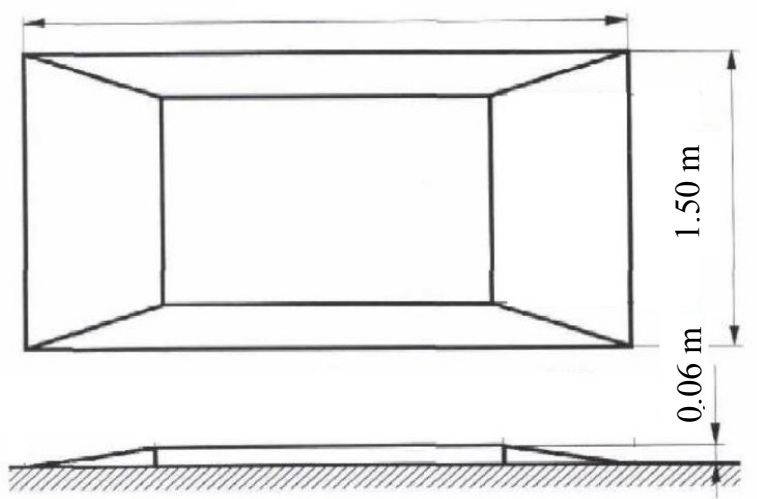

Fig. 1 Schemes of speed bump and speed cushion.

data with a high accuracy and second-by-second frequency. The GPS device provides longitude data to an accuracy of $3 \mathrm{~m}$ and speed measurements to an accuracy of $0.1 \mathrm{~m} / \mathrm{s}$. For the testing purpose, four drivers were employed and each one proceeded at least five drives. The drivers were suggested to drive according to their natural driving patterns and the test vehicle was a passenger car equipped with the GPS device. The field evaluation was carried out during peak-off hours in order to ensure free flow driving and to avoid the interactions with other vehicles or pedestrians. As a result, a number of at least 15 runs for each section was achieved. Speed profiles with abnormal driving patterns caused by the presence of other road users were excluded from further calculations. The data gathered during test rides enable to create speed profiles (Fig. 2).

\section{Data Results and Discussion}

The range of TCM's influence on drivers' speed was assessed through the analysis of an average speed profile derived for each tested location. Fig. 3 presents mean speed profile that reveals disturbances arising from the presence of a speed camera. On the basis of such a profile, it was possible to evaluate the influence zone of each traffic measure as a distance between two points: the beginning point set at the latest point where the drivers' speed remains at a constant level in approach section and the end point where drivers reach again a constant speed. Speed profiles with abnormal driving patterns due to unexpected braking were excluded from calculations of average speed profile.

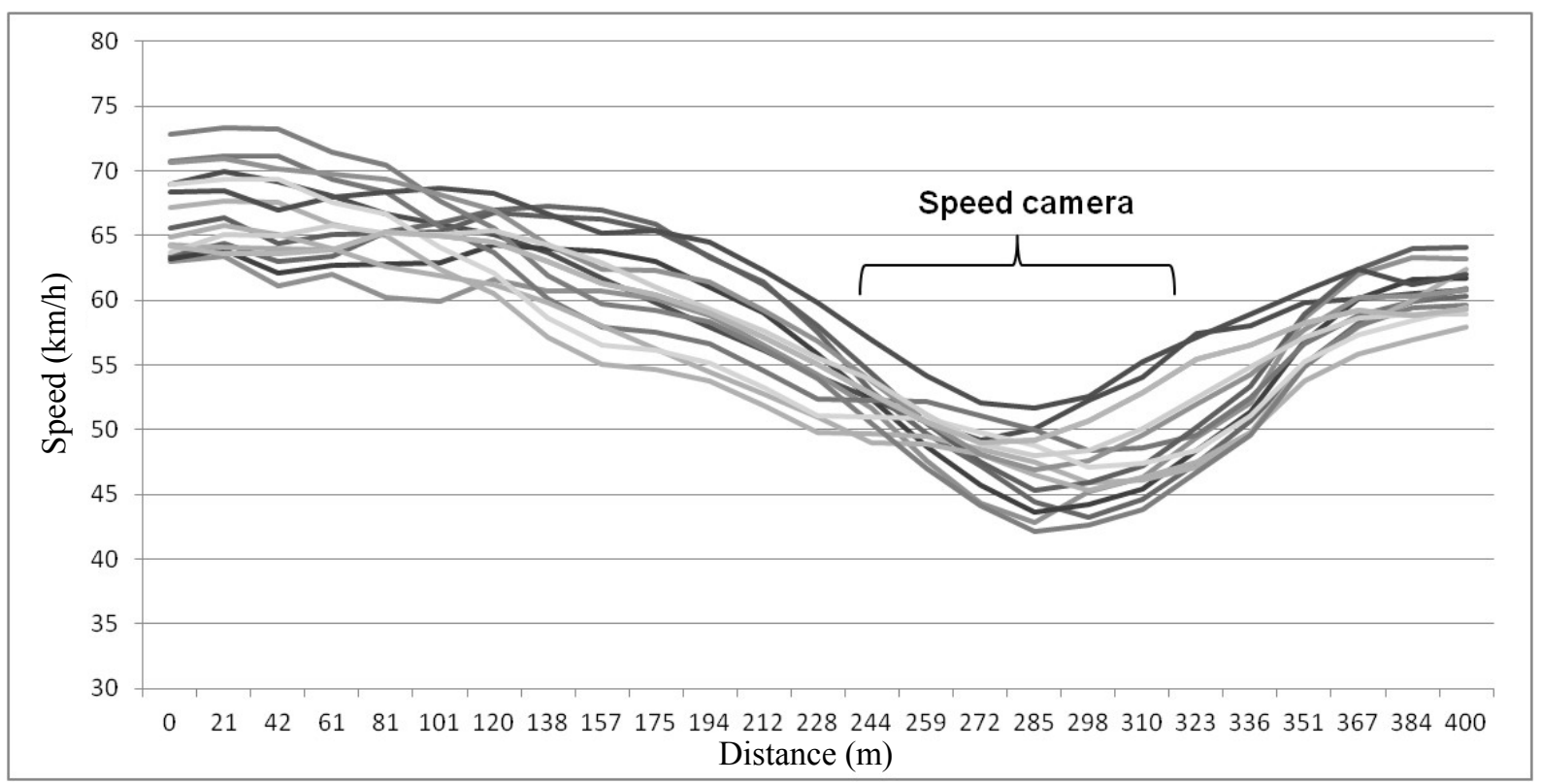

Fig. 2 Individual speed profiles in the vicinity of a speed camera. 


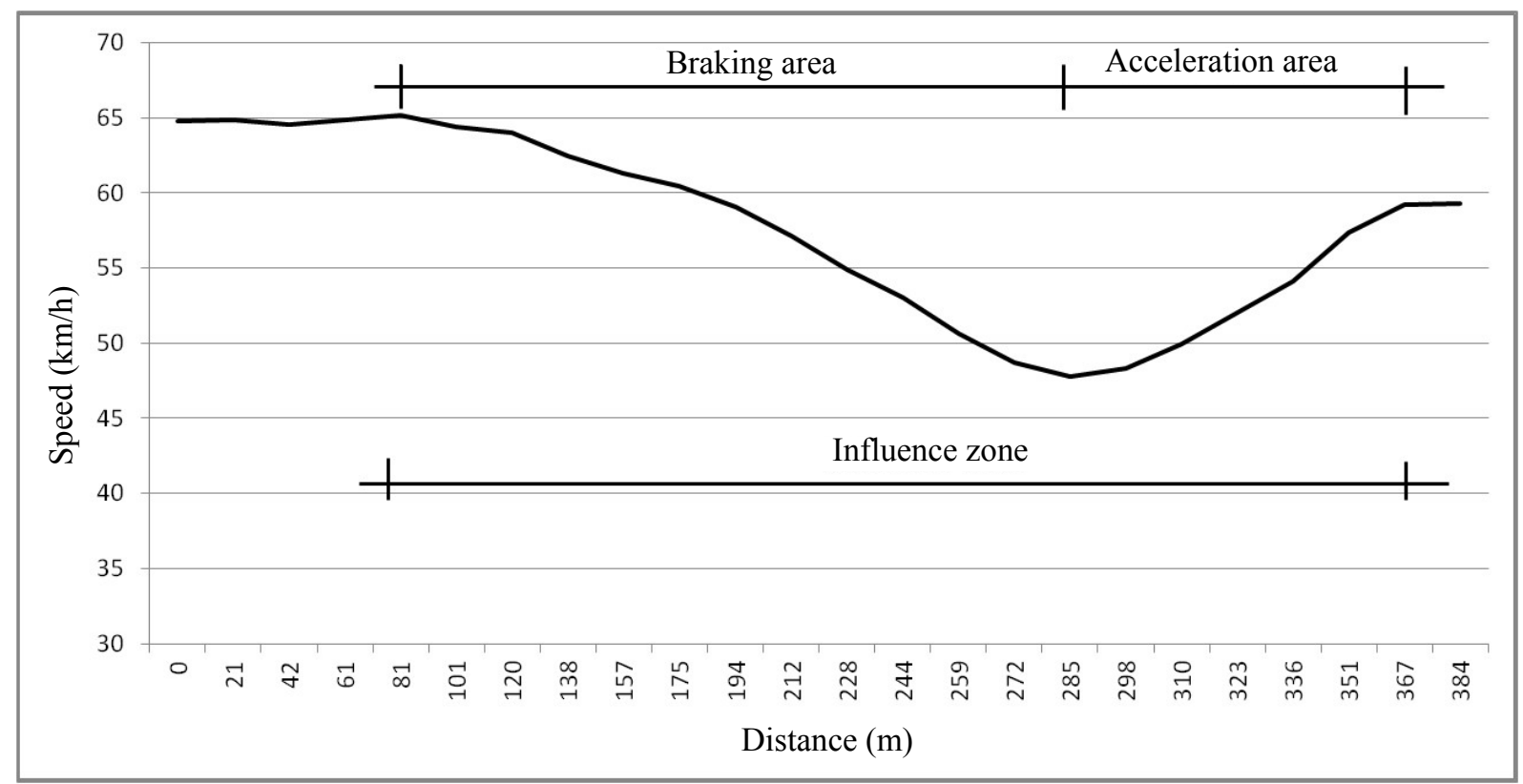

Fig. 3 Average speed profile in the vicinity of a speed camera.

Table 2 Speed characteristics in the vicinity of analysed measures.

\begin{tabular}{|c|c|c|c|c|c|c|}
\hline \multirow{2}{*}{ Traffic calming measure } & \multicolumn{2}{|c|}{ Distance (m) } & \multirow{2}{*}{$\begin{array}{l}\text { Approach } \\
\text { speed }(\mathrm{km} / \mathrm{h})\end{array}$} & \multirow{2}{*}{$\begin{array}{l}\text { Speed over } \\
\text { TCM }(\mathrm{km} / \mathrm{h})\end{array}$} & \multirow{2}{*}{$\begin{array}{l}\text { Speed } \\
\text { reduction }(\%)\end{array}$} & \multirow{2}{*}{$\begin{array}{l}\text { Influence zone } \\
\text { (m) }\end{array}$} \\
\hline & Deceleration & Acceleration & & & & \\
\hline Speed camera & 204 & 82 & 65.1 & 47.7 & 26.7 & 286 \\
\hline Raised intersection & 88 & 149 & 50.6 & 4.9 & 90.3 & 250 \\
\hline Raised pedestrian crossing & 67 & 94 & 40.8 & 7.2 & 82.3 & 167 \\
\hline Speed bump & 53 & 73 & 47.3 & 4.3 & 89.2 & 126 \\
\hline Speed cushion & 101 & 157 & 42.8 & 27.1 & 36.7 & 258 \\
\hline
\end{tabular}

Fig. 2 reveals vehicle's speed in surrounding of speed camera location. Speed reduction takes place in a long section and braking process is mild and devoid of violent acts. Although decrease in the speed at the location of calming device is distinct and reaches $27 \%$ of the approaching velocity, it remains at the lowest level comparing to the other TCMs (Table 2). Fig. 2 demonstrates that drivers, after being forced to reduce the speed before the slow point, try to regain the speed to pre-calming level quite fast and, hence, the area of acceleration is substantially shorter.

Figs. 4-6 present average speed profiles that visibly differ in shape from that presented in Fig. 3. The presence of speed bumps, raised intersection and pedestrian crossing affect the velocity significantly and the average speed at the location of TCMs drops below $10 \mathrm{~km} / \mathrm{h}$ and varies from $4.3 \mathrm{~km} / \mathrm{h}$ to $7.2 \mathrm{~km} / \mathrm{h}$. Drivers attenuating the jolt and expecting the necessity of high speed reduction postpone the braking process as long as possible, hence emerges the short deceleration area. That significant loose of speed creates additionally adverse and rapid braking manoeuvres. Acceleration zones are also short and preset sharp accelerations. Thus, the influence zones are respectively shorter.

Fig. 7 presents an average speed profile along a street where a speed cushion is installed. The speed decrease is distinctly noticeable by drivers but not that much as it happens in the vicinity of other vertical deflections and does not exceed 37\%. The shape of a speed cushion allows vehicles to pass at relatively high speeds which consequently eliminate the necessity of violent manoeuvres.

The aforementioned completely different situation above presents the shape of a speed profile given in Fig. 8 along a street with raised median island installation. 


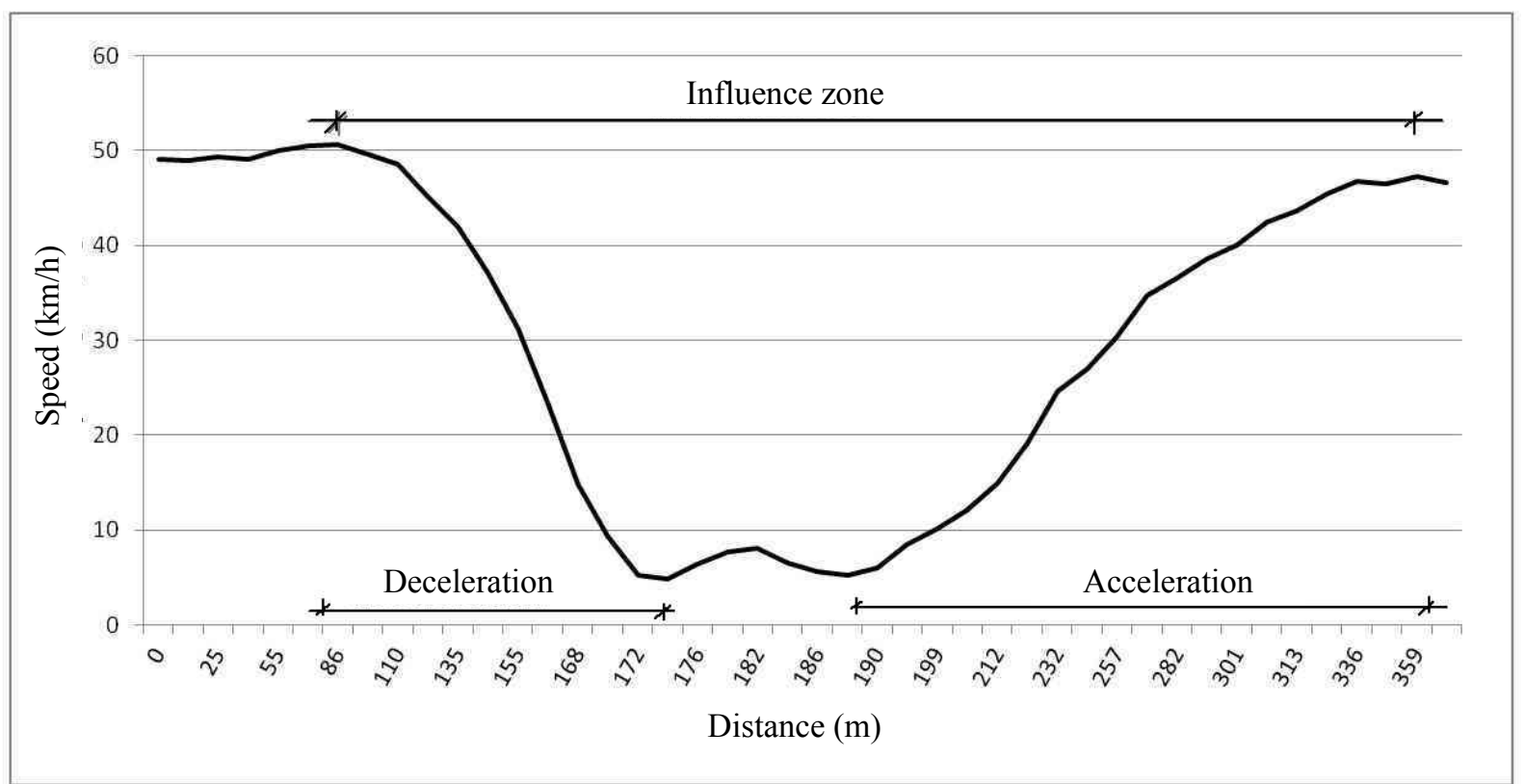

Fig. 4 Average speed profile in the vicinity of a raised intersection.

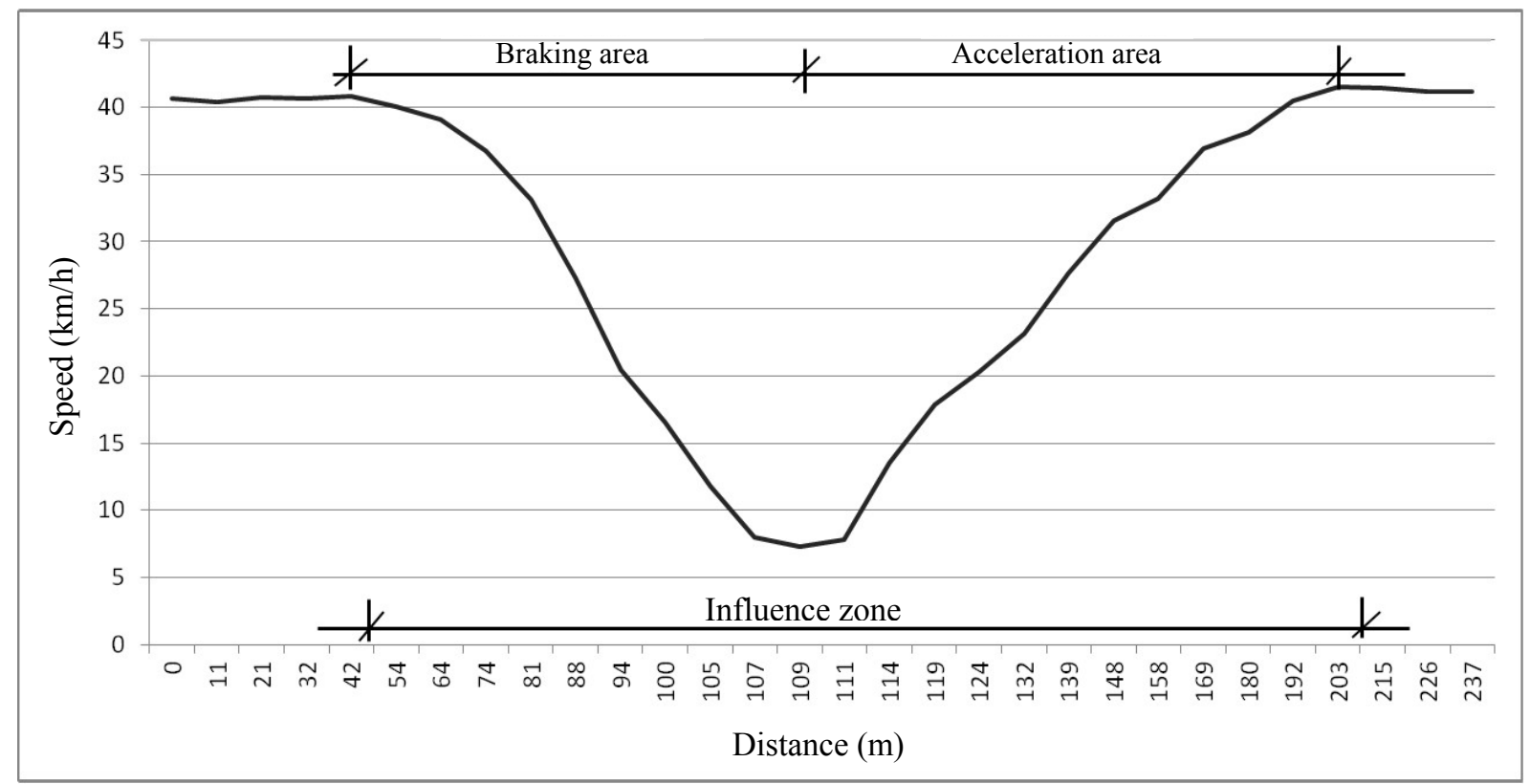

Fig. 5 Average speed profile in the vicinity of a raised pedestrian crossing.

In this situation, variations of speed are negligible and it cannot be said that this results from the presence of median island. The speed fluctuations are within the range of $1 \mathrm{~km} / \mathrm{h}$ and local decreases take place not only in the vicinity of the slot point but also before and after.

Elaborated speed profiles are used to determine deceleration and acceleration sections presented in
Table 2.

Speed profiles allow to estimate TCM's influence area as a summarized distance of braking and acceleration processes. The results in Table 2 reveal that depending on the type of calming measure, the influence area ranges from $126 \mathrm{~m}$ to $286 \mathrm{~m}$. Concerning the effectiveness of analysed devices in scope of a distance which they impact on vehicle's 
speed, a speed camera has occurred to be the most effective tool $(286 \mathrm{~m})$ while the least effective, although their efficiency in speed reduction was high, was speed bumps $(126 \mathrm{~m})$. The influence zone of a speed cushion $(258 \mathrm{~m})$ is comparable with that of a raised intersection $(250 \mathrm{~m})$ but considering their effectiveness in range of a speed reduction, it presents much different effectiveness. The presence of raised intersection disturbs the traffic flow and smoothness much severer (speed reduction by 90.3\%) than speed cushion (speed reduction by $36.7 \%$ ) and is less welcome by the drivers. The influence zone of a raised pedestrian crossing $(167 \mathrm{~m})$ comparing to a speed camera, speed cushion and raised intersection is much shorter and also results in high speed reduction (89.2\%).

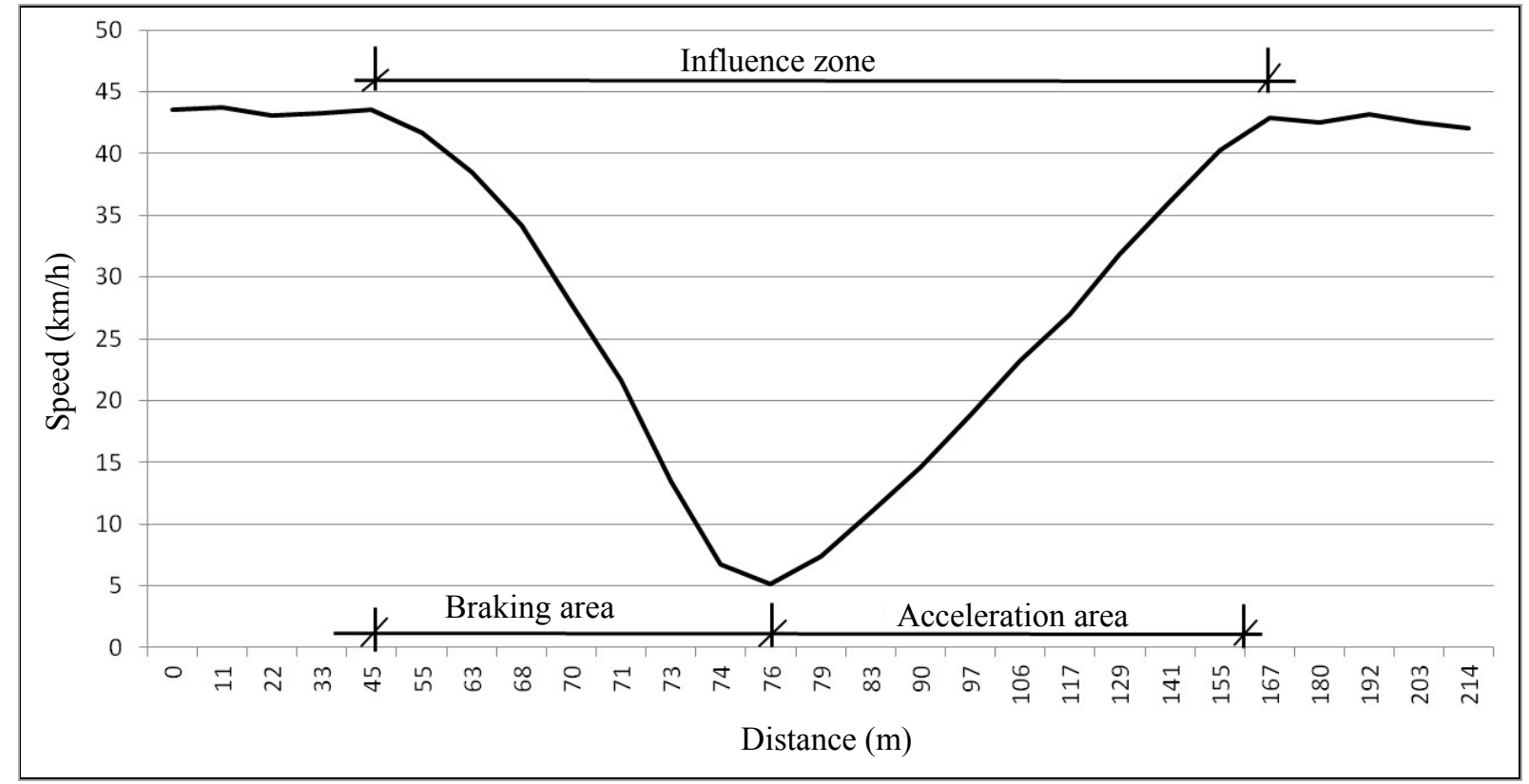

Fig. 6 Average speed profile in vicinity of a speed bump.

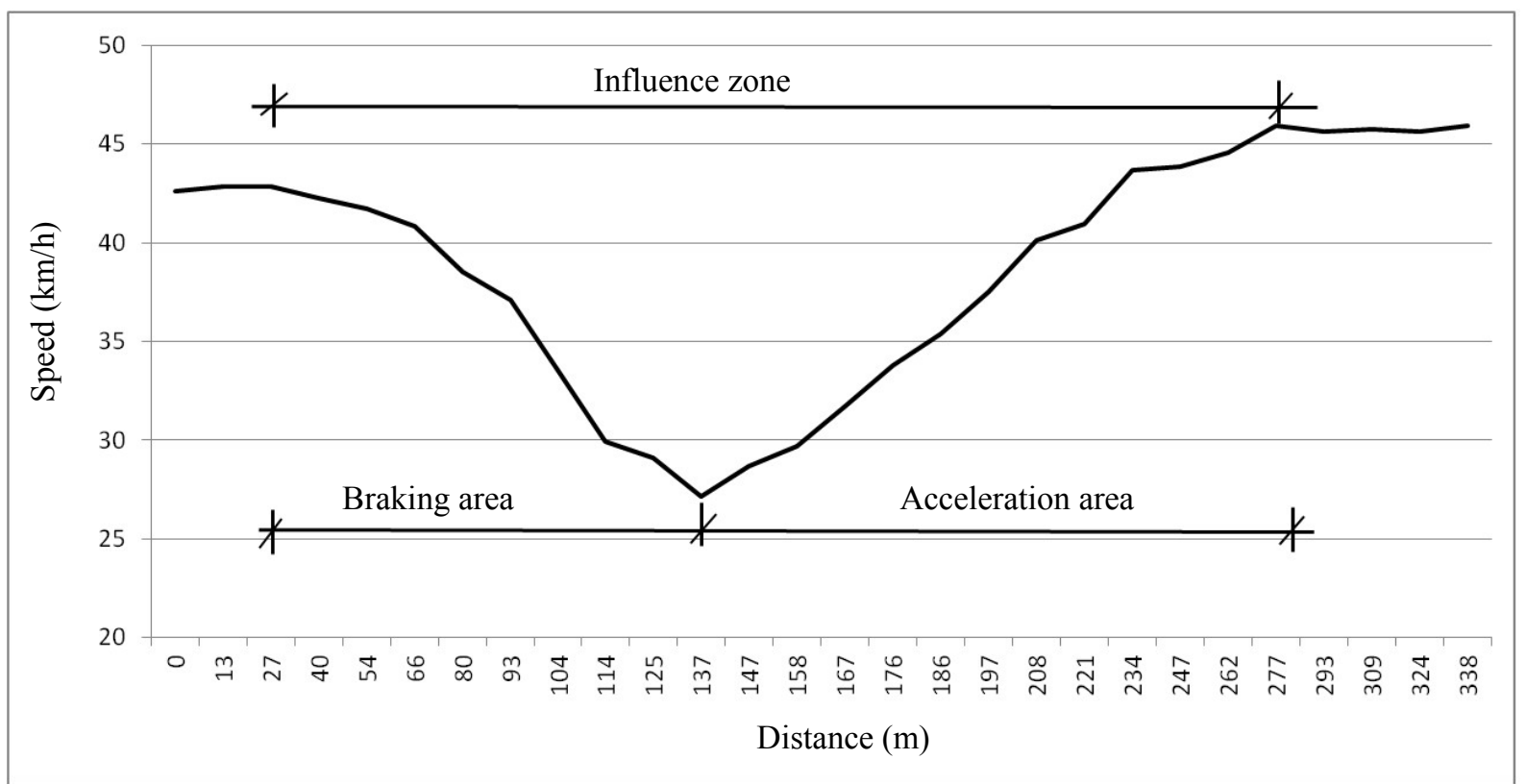

Fig. 7 Average speed profile in the vicinity of a speed cushion. 


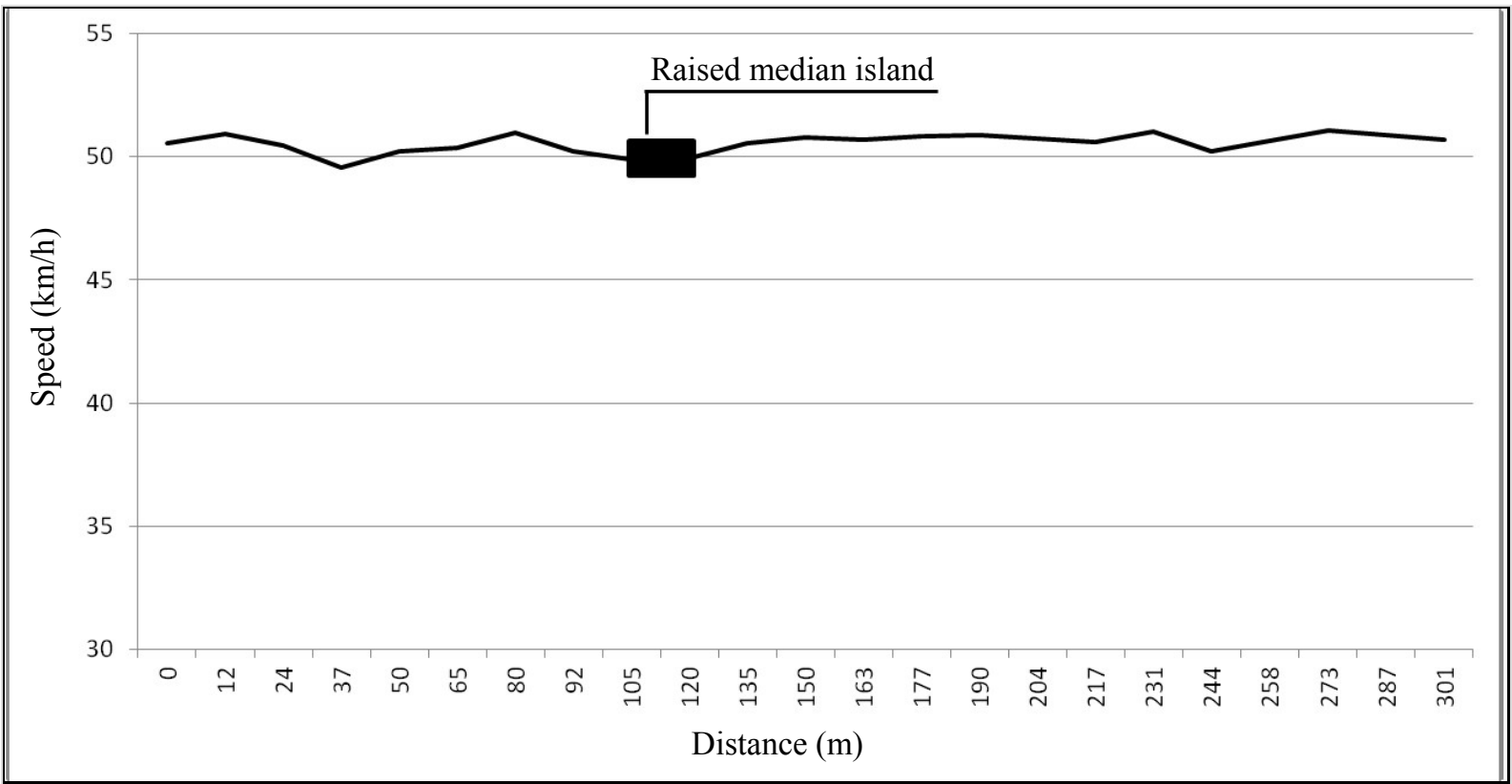

Fig. 8 Average speed profile in the vicinity of a raised median island.

The presence of a speed camera provides not only the longest braking section but also prevents other drivers on the road from unexpected and adverse rapid braking. On the other hand, the shortest influence zone is related to aggressive driving, rapid braking and acceleration manoeuvres. This situation occurs in the vicinity of most frequently used speed bumps for which braking zone is $53 \mathrm{~m}$. In case of a speed cushion and raised intersection, although braking distances are much shorter comparing to a braking distance before a speed camera, the influence zones are highly comparable due to longer acceleration areas.

\section{Conclusions}

Installation of traffic calming measures aims at improving traffic safety and environmental impacts, and should be considered in many aspects. This study presents the estimation of traffic measurements' effectiveness in terms of influencing zone with the usage of speed profiles derived from test rides along streets with various calming device installations in the city of Bialystok. Achieved results show that speed profiles can be a useful tool in assessment of traffic calming measures efficiency in that scope.
Most frequently used calming devices in Bialystok are speed bumps mainly due to low implementation costs. The research results proved that although effectiveness in speed reduction is high, their usage is questionable concerning the influencing zone and also disturbances in traffic smoothness they cause. Considering calming measures in terms of influencing zone and existing conditions, the most effective within analysed is speed camera, while within vertical deflections, the most reasonable is the use of speed cushion whose presence does not cause great disturbance in driving style and effectively influence drivers' speed in a long distance. Therefore, installation of speed bumps despite their low installation costs should be deeply considered because they affect vehicle's speed for a short distance and create conditions for abrupt manoeuvres and aggressive driving style.

Speed profiles allow to estimate not only the range of influence but also enable to evaluate driving style which can greatly affect on emission levels and environmental impact, so the knowledge of drivers' behaviour in vicinity of various calming measures can be valuable for local road administration in early stage of new schemes planning. 


\section{References}

[1] Speed Management Report for the Organization for Economic Co-operation and Development, in: European Conference of Ministers of Transport, OECD (Organization for Economic Co-operation and Development), 2006.

[2] WHO (World Health Organization), Global Status Report on Road Safety: Time for Action [Online], World Health Organization, Geneva, 2009, www.who.int/violence injuryprevention/roadsafetystatus/2009 (accessed Mar. 15, 2014).

[3] H.M. Barbosa, Impacts of traffic calming measures on speeds on urban areas, Ph.D. Thesis, Institute for Transport Studies, University of Leeds, 1995.

[4] A.R. Hodge, A review of the $20 \mathrm{mile} / \mathrm{h}$ speed zones, Traffic Engineering and Control 10 (1992) 545-547.

[5] Traffic Calming, State of the Practice ITE (Institute of Transportation Engineers)/FHWA (Federal Highway Administration), FHWA, Washington, 1999.

[6] Traffic Calming, Local Transport Note 1/07, Department for Transport, TSO (The Stationery Office), London, 2007.

[7] C.J. Lines, Road humps for the control of vehicle speeds, Traffic Engineering and Control 1 (1993) 2-7.

[8] R.E. Layfield, D.I. Parry, Traffic Calming: Speed Cushion Schemes, TRL report 312, Transport Research Laboratory, UK, 1998.

[9] D.C. Webster, R.E. Layfield, Traffic Calming - Sinusoidal, "H" and "S" Humps, TRL report 377, Transport Research Laboratory, UK, 1998.

[10] M. Pau, S. Angius, Do speed bumps really decrease traffic speed? An Italian experience, Accident Analysis and Prevention 33 (2001) 585-597.

[11] C. Arien, K. Brijs, T. Brijs, W. Ceulemans, G. Vanroelen, E.M.M. Jongen, et al., Does the effect of traffic calming measures endure over time?-A simulator study on the influence of gates, Transportation Research Part F 22 (2014) 63-75.

[12] A.A. Vis, A. Disjkstra, A. Slp, Safety effects of $30 \mathrm{~km} / \mathrm{h}$ zones in the Netherlands, Accident Analysis \& Prevention 24 (1992) 75-86.

[13] T. Litman, Traffic Calming Benefits, Costs and Equity Impacts, Victoria Transport Policy Institute, USA, 1999.

[14] W.D. Cottrell, N. Kim, P.T. Martin, H.J. Perrin, Effectiveness of traffic management in Salt Lake City, Utah, Journal of Safety Research 37 (2006) 27-41.

[15] R. Elvik, Area-wide urban traffic calming schemes: A meta-analysis of safety effects, Accident Analysis and Prevention 33 (2001) 327-336.

[16] A.T. Moreno, A. García, Use of speed profile as surrogate measure: Effect of traffic calming devices on crosstown road safety performance, Accident Analysis and Prevention 61 (2013) 23-32.

[17] H.M.M. Barbosa, M.R. Tight, A.D. May, A model of speed profiles for traffic calmed roads, Transportation Research Part A 34 (2000) 103-123.

[18] G. Lee, S. Joo, C. Oh, K. Choi, An evaluation framework for traffic calming measures in residential areas, Transportation Research Part D 25 (2013) 68-76.

[19] R. Ziolkowski, Wpływ środków uspokojenia ruchu na prędkość pojazdów w warunkach miejskich (Influence of traffic calming measures on speed in cities), Transport Review 4 (2012) 24-30. (in Polish) 